\title{
VALOR NUTRICIONAL DE FARINHA DE SOJA E MEL, FARINHA LÁCTEA E AÇÚCAR EM COLMÉIAS DE ABELHAS (Apis mellifera ) NA PRODUÇÃO DE GELÉIA REAL
}

\author{
NUTRITIONAL VALUE OF SOYBEAN MEAL, HONEY, MILKY MEAL AND SUGAR \\ AT BEEHIVES (Apis mellifera) IN THE PRODUCTION OF ROYAL JELLY
}

\author{
Tarcizio Antonio Perlin ${ }^{1}$
}

RESUMO

O experimento foi realizado no apiário Padre Assis, no Município de Santiago, RS, no período entre 10 de dezembro de 1996 a 10 de janeiro de 1997. Foram utilizadas vinte colméias Langstroth, cada uma com dois ninhos separados por tela excluidora de rainhas. As unidades experimentais foram colméias sobre as quais os tratamentos alimentares foram aplicados em um delineamento inteiramente casualizado. Os efeitos dos tratamentos foram avaliados pelo desempenho das colméias na produção de geléia real e os dados submetidos à análise de variância e ao teste Tukey. A relação entre o consumo do alimento e a produção de geléia real, resultou no Tratamento-1 com uma produção média de 7,9 gramas de geléia real por colméia em cada coleta; no Tratamento-2, a produção ficou em 4,32 gramas por coleta. Os resultados obtidos evidenciaram que o aproveitamento dos apiários na região central do Rio Grande do Sul, para a produção de geléia real nos meses de dezembro e janeiro, é economicamente viável, utilizando-se alimentação suplementar constituída de três partes de açúcar e uma de farinha láctea.

Palavras-chave: geléia real, produção, colméias.

\section{SUMMARY}

The experiment was realized in Padre Assis' apiary, at Santiago county Brazil, from December 10, 1996 to January 10, 1997. Twenty Langstroth beehives with two separeted nests by an excluding screen of queen bees were used. The experimental unity was constituted of beehives in which treatments were applied randomly. The effects of treatments were evaluated through the beehives performance of production of royal jelly and the data were submitted to the analysis of variance and the test of Tukey. The relation between feed consumption and royal jelly production, resulted in the treatment-1, average production of
$7.9 \mathrm{~g}$ of royal jelly/beehive of each harvest, in treatment-2 the production was of $4.32 \mathrm{~g}$. These results evidenced that the use of apiaries of the central region of Rio Grande do Sul, for royal jelly production in December and January is practicable. This results were achieved with the utilization of supplemental feeding constituted of three parts of sugar and one of milky meal.

Key words: royal jelly, production, beehives.

\section{INTRODUÇÃO}

Um dos fatores que mais concorrem para o sucesso da apicultura, no Rio Grande do Sul, é a alimentação suplementar das abelhas. A farinha de soja é adequada à criação de larvas de abelhas quando oferecida como única fonte de proteína no alimento (SHIMANUKI et al., 1985) em regimes alimentares contendo $23 \%$ de proteína. Na escolha dos ingredientes de uma alimentação suplementar para as abelhas (IOIRICH, 1986), deve-se optar ainda por alimentos que possuam gosto e aroma agradáveis.

No presente trabalho, buscou-se comparar a produção de geléia real em colméias alimentadas com uma mistura de farinha de soja e mel com uma mistura de farinha láctea e açúcar. Procurou-se fornecer dados para o aproveitamento dos apiários no período de escassez de alimentos na região central do estado do Rio Grande do Sul (RS), isto é, nos meses de dezembro e janeiro.

\footnotetext{
${ }^{1}$ Médico Veterinário, Mestre em Zootecnia, Professor Titular, Pró-reitoria de Extensão, Universidade Federal de Santa Maria (UFSM),
} 97105-900, Santa Maria, RS. E-mail: perlin@adm.ufsm.br. 


\section{MATERIAL E MÉTODOS}

O trabalho foi desenvolvido no Apiário Padre Assis, Distrito da Linha - 8, no município de Santiago, RS, no período compreendido entre 10 de dezembro de 1996 e 10 de janeiro de 1997. Foram utilizadas 20 colméias, 10 para cada experimento, escolhidas ao acaso de um grupo de 45 colméias em produção de geléia real.

Após a coleta, as cúpulas vazias foram raspadas, quando, então, foi colocado no centro do fundo de cada cúpula uma gotícula de uma mistura de geléia real e água destilada em partes iguais, sobre a qual foi depositada uma larva transferida. Cada colméia recebeu um quadro porta-cúpulas com 35 cúpulas plásticas de $9 \mathrm{~mm}$, soldadas com cera de abelhas. Foram utilizadas larvas de uma única colméia, nas cúpulas enxertadas, embora BAUMGRATZ (1992) afirme que a origem de larvas de diversas colméias não exerce influência sobre a produção de geléia real.

As larvas transferidas na enxertia das cúpulas tinham menos de 36 horas de vida e foram agarradas por trás, introduzindo por baixo, num movimento deslizante, a parte achatada do estilete, até levantá-la, segundo o procedimento de HOOPNER (1976), o que deve ser realizado, segundo WIESE (1980), com muita perícia e cuidado, evitando a morte da larva. Todas as enxertias de cúpulas foram realizadas pelo mesmo operador. A coleta da geléia real foi realizada após 60 horas de cada enxertia, num total de 12 coletas no período experimental.

A farinha láctea, de origem comercial, foi misturada ao açúcar refinado em $10 \%$ de água e aquecido em uma panela sobre fogo direto, até o ponto de fervura.

Durante o tratamento-1, dez colméias receberam uma alimentação com 3,4 \% de proteína bruta, composta de uma mistura de $1 \mathrm{~kg}$ de farinha láctea com $03 \mathrm{~kg}$ de açúcar refinado; no tratamento2 , as demais colméias receberam uma alimentação com $26,66 \%$ de proteína bruta, formada pela mistura de $2 \mathrm{~kg}$ de farinha de soja com $1 \mathrm{~kg}$ de mel (tabela 1 ), oferecida à vontade em alimentadores tipo bandeja. A farinha de soja, de origem não comercial, foi preparada com grãos da variedade Santa Rosa, cultivada em lavouras próprias, sem a utilização de agrotóxicos em todas as fases do cultivo. Os grãos foram torrados em uma panela, sobre fogo direto e triturados até a formação de uma farinha com granulometria entre 400 a 700 micrômetros, quando então foram misturados ao mel.
Tabela 1 - Composição das rações experimentais utilizadas na suplementação alimentar de colméias (Apis mellifera) durante o tratamento1 (T-1) e tratamento-2 (T-2) na produção de geléia real.

TRATAMENTO \% DE PROTEÍNA INGREDIENTES \% USADO BRUTA

3,40

26,66
$\mathrm{T} 1$

T 2

$\begin{array}{cl}\text { Farinha láctea * } & 25 \\ \text { Açúcar refinado } & 75 \\ \text { Farinha de soja } & 66,67 \\ \text { Mel } & 33,33\end{array}$

Segundo o fabricante ( Nestlé): 13,6 \% de proteína bruta.

*Segundo análises: $40 \%$ de proteína bruta.

1- 10 colméias em produção de geléia real por 30 dias. T2- 10 colméias em produção de geléia real por 30 dias.
Foi utilizado o delineamento inteiramente casualizado e a unidade experimental foi a colméia. Os parâmetros estimados foram: produção de geléia real, consumo do alimento e cúpulas cheias. Os dados obtidos foram analisados utilizando o programa SAS (1989). Foram feitas análises de variância ao nível de significância de 5\%. Foi aplicado o teste Tukey para a comparação entre as médias dos tratamentos.

\section{RESULTADOS E DISCUSSÃO}

As abelhas aceitaram o alimento sem maiores problemas de consumo e a procura do alimento foi normal em nossas observações, embora HAYDAK (1970) recomende que o alimento substituto seja oferecido antecipadamente nos favos, para que as abelhas nutrizes do ninho se acostumem com o odor estranho e o gosto do alimento, quando o mesmo é oferecido em forma de pasta. As características dos alimentos estão de acordo com MILLS (1981) quanto ao sabor agradável, a consistência, a facilidade do preparo e o custo baixo

A média de produção da geléia real, a cada 60 horas, por coleta durante o tratamento- 1 foi de 7,90 gramas por dez colméias e a média durante o tratamento-2 foi de 4,32 gramas (tabela 2).

Esses resultados estabelecem uma relação de consumo do alimento em 72,71 gramas de alimento consumido para cada grama de geléia real produzida no tratamento -1 e 11,20 gramas de alimento consumido por grama produzida no tratamento-2.

A porcentagem de preenchimento das cúpulas oferecidas foi significativo no tratamento-1, que apresentou $81,02 \%$ de cúpulas aceitas em relação ao Tratamento-2, que foi de 54,51 \% de cúpulas 


\begin{tabular}{|c|c|c|c|c|}
\hline TRATAMENTOS & PRODUÇÃO MÉDIA & $\begin{array}{l}\text { PRODUÇÃO } \\
\text { TOTAL }\end{array}$ & $\begin{array}{l}\text { CONSUMO DE ALIMENTO POR } \\
\text { GRAMA DE GELÉIA REAL }\end{array}$ & \% CÚPULAS ACEITAS \\
\hline $\mathrm{T}-1$ & 7,90 & 948,90 & 72,71 & 81,00 \\
\hline $\mathrm{T}-2$ & 4,32 & 518,40 & 11,20 & 54,50 \\
\hline
\end{tabular}

aceitas ( $p>0,0001)$. Essa observação apoia-se no trabalho de LEVY et al. (1990), segundo o qual a produção final de geléia real é influenciada somente pela porcentagem de cúpulas aceitas e não pela produção individual das cúpulas, pois esta apresenta pouca variação entre as colônias.

A ocorrência de maior insolação e radiação solar durante o período em que foi realizado o experimento favoreceu o preenchimento das cúpulas, o que, segundo LENGLER (1979), influencia significativamente a atividade global das abelhas, indicado pelo aumento dessa atividade no verão.

\section{CONCLUSÃO}

A farinha láctea misturada ao açúcar refinado apresenta-se viável para ser utilizada como suplementação alimentar na produção de geléia real, viabilizando o aproveitamento dos apiários para a produção de geléia real nos meses de dezembro e janeiro na localidade do experimento.

\section{REFERÊNCIAS BIBLIOGRÁFICAS}

BAUMGRATZ, L.L. Utilização de abelhas africanizadas ( Apis mellifera L.1758) em diferentes técnicas de produção de geléia real. Lavras- MG. 70 p.Tese (Mestrado em Zootecnia) - Curso de Pós-graduação em Zootecnia, Escola Superior de Agricultura de Lavras, 1992.
HAYDAK, M. Alimentacion de las abejas y los substitutos de polen, Apiacta V, Romênia, v. 3, p. 8-9, 1970.

HOOPNER, T. Guia do apicultor. 4.ed. Portugal: Publicações Euro-América, 1976. 266 p.

IOIRICH,N. P. As abelhas farmacêuticas com asas. 2. ed. URSS: Mir, 1986. 248 p.

LENGLER, S. Comportamento de linhagens de abelhas (Apis mellifera) na região de Santa Maria ( RS ). Santa Maria R.S. 57 p. Tese (Mestrado em Zootecnia ) - Curso de Pósgraduação em Zootecnia, Universidade Federal de Santa Maria, 1979.

LEVY, P.S., SILVA, R.M.B., PARANHOS, B.A.J. Influência do tempo entre a transferência de larvas e a colheita, sobre a produtividade de geléia real de abelhas africanizadas. Revista Brasileira de Apicultura, n. 39, p. 26, 1990.

MILLS, J.A. Alimentacion de las abejas: um importante metodo de mantenimiento para desarrolar colonias fuertes. Apiacta XVI, Romênia, v. 3, p. 116-118, 1981.

SAS - Statistical Analysis System. User's Guide. Version 6. SAS INSTITUTE INC. 4.ed. North Caroline: SAS INSTITUTE INC., 1989, 846 p.

SHIMANUKI,H., HERBERT,E.W. Alimento artificial con proteinas para las colonias de abejas. In: XXX CONGRESSO INTERNACIONAL DE APICULTURA, 1985. Nagoya, Japão. Anais... Nagoya, 1985. 320 p., p.131-135.

WIESE, H. Nova Apicultura. 2.ed. Porto Alegre: Agropecuária, 1980. 247 p.

Ciência Rural, v. 29, n. 2, 1999. 